\title{
An Analysis Based on Social Capital Theory on Health Conditions of Elderly People and Influencing Factors in Tianjin Area
}

\author{
Wang Xiaofang \\ Tianjin University of Traditional Chinese Medicine \\ TJUTCM \\ Tianjin, China \\ 1468630344@qq.com \\ Ma Yale \\ Tianjin University of Traditional Chinese Medicine \\ TJUTCM \\ Tianjin, China \\ 1641844230@qq.com
}

\author{
Li Ying \\ Tianjin University of Traditional Chinese Medicine \\ TJUTCM \\ Tianjin, China \\ 714837702@qq.com
}

\author{
Li Lancui \\ Tianjin Huanhu Hospital \\ Tianjin, China \\ excellent998@163.com
}

\author{
He Qiang* (Corresponding Author) \\ Tianjin University of Traditional Chinese Medicine \\ TJUTCM \\ Tianjin, China \\ heqiangmail@126.com
}

\begin{abstract}
The aim of this paper is to comprehend health conditions of elderly people and figure out what's the influencing factors in Tianjin area and explore the relationship between social capital and health conditions. Then practical social advice is purposely given to improve life conditions of elderly people. The paper is illustrated by questionnaires given to elderly people over 60 in parks, gardens, gyms and other public places in Tianjin. Result: According to ordinal category data Logistic, age, participating insurance, degree of education, social trust and the public participation influence health conditions of elderly people. Conclusion can be drawn that educational propagandas and recreational activities in community should be carried out regularly, then social trust and the public participation of the elderly people in communities should be increased while the medical insurance of the elderly people's self-payment should be decreased and we should consummate the procedure of the medical insurance payment to make it more easy and normal.
\end{abstract}

Keywords-Social capital, health condition, the elderly people, Tianjin area

\section{INTRODUCTION}

According to the sixth demographic census ${ }^{[1]}$ released by National Bureau of Statistics, by the time Sep. 11, 1th, 2010, the elderly people over 60 account for $13.26 \%$, which is $2.93 \%$ more than that in 2010, and those over 65 account for $8.87 \%$, which is $1.91 \%$ more than that in 2000 . As is authoritatively published that China will achieve the highest level of an aging population by 2030. UK and USA and other countries have made social capital a significant measure to improve individual psychology, and improve social network to increase health by volunteering activities ${ }^{[2]}$. As a result, it is urgent to have "successful aging" be sound. Under the circumstance that tangible material resources are not enough, social capital, as intangible resources implanted into social relationship, has become a new entry point to ease the current aging problem. With the development of economy and society, the elderly people have become a gradually increasing crowd, and the health problems of them have become an unavoidable issue. The research analyses the health conditions of the elderly people in Tianjin area and affecting factors, based on social capital, and then related policy suggestions are given.

\section{OBJECT AND METHODS}

\section{A. Object}

Questionnaires are given to the elderly people over 60 in Tianjin areas in parks, gardens, gyms, etc. 21 out of 309 are below standard, and $90 \%$ of the questionnaires are valid.

\section{B. Methods}

Questionnaires designed according to related pertinent literature ${ }^{[3-6]}$ is finalized pre-investigate and survey, including social capital clauses, health conditions clauses and sociology of population information. Social capital includes social credibility, public participation and social network relationship, with 11 clauses on health conditions. 


\section{Data processing}

Data is logged by EpiData3.1 and then related data is analyzed by Stata13.0. Scores are given on respondents' health conditions, and the scores are divided into three groups according to their health conditions. Kruskal-Wallis is used to examine the differences of health conditions on elderly people with distinctions, three dimensionalities of social capital and statistically significant factors are worked as independent variable then presenting an orderly classification more Logistic regression analysis.

\section{RESULTS}

\section{A. Basic information about surveyed elderly people}

Among 288 respondents, ages distribute (70.3 \pm 7.4$)$ and monthly income distributes (2721.2 \pm 1549.0$)$ Yuan. Males are 187 (64.9\%) and female are101 (35.1\%), with Han nationality 277 (96.9\%)and minority 9(3.1\%) and 2 with no nationality information. See table I.

TABLE I. Surveys ON SOCIOLOGY BASIC CHARACTERISTICS OF THE ELDERLY PEOPLE.

\begin{tabular}{|c|c|c|c|}
\hline \multicolumn{2}{|r|}{ Features } & \multirow{2}{*}{$\begin{array}{l}\text { Number } \\
187\end{array}$} & \multirow{2}{*}{$\begin{array}{l}\text { Percentage(\%) } \\
64.9\end{array}$} \\
\hline & Male & & \\
\hline Gende & Female & 101 & 35.1 \\
\hline \multirow{2}{*}{ Nationality } & Han & 277 & 96.9 \\
\hline & Minority & 9 & 3.1 \\
\hline \multirow{4}{*}{ Education degree } & Primary and below & 40 & 13.9 \\
\hline & Junior school and below & 102 & 35.4 \\
\hline & Senior school or technical secondary school & 94 & 32.6 \\
\hline & College and above & 51 & 17.8 \\
\hline \multirow{4}{*}{ Career before retirement } & State organs, public institutions & 64 & 22.5 \\
\hline & Enterprise employees, professional and technical personnel & 177 & 62.1 \\
\hline & Business, service personnel & 24 & 8.4 \\
\hline & Agriculture, forestry, animal husbandry and fishery, water conservation, production personnel & 19 & 6.7 \\
\hline \multirow{5}{*}{ Medical insurance } & None & 16 & 5.6 \\
\hline & Urban residents' basic medical insurance & 55 & 19.2 \\
\hline & Urban workers basic medical insurance & 189 & 65.9 \\
\hline & Free medical service & 22 & 7.7 \\
\hline & Commercial insurance & 2 & 0.8 \\
\hline
\end{tabular}

\section{B. Social capital conditions of the elderly people}

In the social credibility dimension, good, normal and bad credibility covers $13.9 \%, 50.0 \%$ and $36.1 \%$, in the public participation dimension, with good participation $12.9 \%$, normal $41.3 \%$, and bad $45.8 \%$. In the social network connection dimensions, with good $8.7 \%, 33.3 \%$ and bad $58.0 \%$. See table II.

TABLE II. SOCIAL CAPITAL DIMENSIONS

\begin{tabular}{|l|l|l|l|}
\hline \multirow{2}{*}{ Dimensions } & \multicolumn{3}{|c|}{ Level } \\
\cline { 2 - 4 } & \multicolumn{1}{|c|}{ Good } & Normal & Bad \\
\hline Social credibility & $40(13.9 \%)$ & $144(50.0 \%)$ & $104(36.1 \%)$ \\
\hline Public participation & $37(12.9 \%)$ & $119(41.3 \%)$ & $132(45.8 \%)$ \\
\hline Social network connection & $25(8.7 \%)$ & $96(33.3 \%)$ & $167(58.0 \%)$ \\
\hline
\end{tabular}

\section{Surveys on the health conditions of the elderly people}

The health conditions of the elderly people cover activity, self-care, daily activity, pains and anxiety, and other 11 clauses. Generally speaking, $81.9 \%$ of the elderly people are satisfied with life, $14.6 \%$ feeling general, and 3.5\% unsatisfied with life. No one feels extremely unsatisfied. When asked whether they will make sure many times about something, $21.2 \%$ of them answer it is always and 31.3\% answer it is often, 20.1\% answer it is sometimes, $11.8 \%$ answer it is hardly and $15.6 \%$ answer it is never. There exists $39.0 \%$ having no chronic diseases and $61.0 \%$ having chronic diseases, with 1 person missing information.
$93.0 \%$ of the elderly people can get around, whole $7 \%$ of them have some action inconvenience. $86.3 \%$ of the elderly people can care themselves, while $13.2 \%$ of them have some trouble taking care of themselves. $92.7 \%$ of them can do basic daily activities, $6.6 \%$ can nearly do, $0.7 \%$ can't. $37.9 \%$ have good sleeping quality, with $48.6 \%$ normal and $13.5 \%$ bad. $36.1 \%$ have good memory while $49.7 \%$ have normal memory and $14.2 \%$ have bad memory. The elderly people with no pain covers $41.7 \%$ and moderate pain covers $59.6 \%$ and extreme pain covers $1.4 \%$. Those who don't feel nervous or depressed cover $63.8 \%$, those who feel moderate nervous or depressed cover $34.5 \%$ and those who feel extremely nervous or depressed cover $1.7 \%$. Self-reported health status for the good elderly people accounts for 58.8\%, normal elderly people 
accounts for $33.9 \%$, bad elderly people accounts for $7.3 \%$. See $\quad$ table III.

TABLE III. SURVEYS ON THE HEALTH CONDITIONS OF THE ELDERLY PEOPLE

\begin{tabular}{|l|l|l|l|l|l|l|}
\hline \multirow{2}{*}{ Clauses } & \multicolumn{2}{c|}{ Good } & \multicolumn{3}{c|}{ Normal } & \multicolumn{3}{c|}{ Bad } \\
\cline { 2 - 8 } & Number & $\%$ & Number & \% & Number & $\%$ \\
\hline Getting around: & 266 & 93.0 & 20 & 7.0 & 0 & 0.0 \\
\hline Self- care: & 250 & 86.8 & 38 & 13.2 & 0 & 0.0 \\
\hline Daily activity: Basic daily activities can be performed: & 265 & 92.7 & 19 & 6.6 & 2 & 0.7 \\
\hline Pain/ discomfort: & 120 & 41.7 & 164 & 56.9 & 4 & 1.4 \\
\hline Anxiety/ depression: & 183 & 63.8 & 99 & 34.5 & 5 & 1.7 \\
\hline Sleeping quality: & 109 & 37.9 & 140 & 48.6 & 39 & 13.5 \\
\hline Health conditions compared to peers: & 168 & 58.8 & 97 & 33.9 & 21 & 7.3 \\
\hline Memory status: & 104 & 36.1 & 143 & 49.7 & 41 & 14.2 \\
\hline
\end{tabular}

\section{Single-factor analysis of the elderly people's health} conditions

The health conditions are divided into three parts, and 87people (30.2\%) are good, 106people (36.8\%) are normal, and 95 people (33.0\%) are bad. Kruskal-Wallis is used to examine the differences of health conditions among the elderly people: age, education level, career before retirement, monthly pension, insurance, social trust and public participation have statistically difference $(\mathrm{P}<0.05)$. See table IV.

TABLE IV. COMPARISON OF HEALTH CONDITION LEVELS AMONG THE ELDERLY PEOPLE WITH DIFFERENT FEATURES

\begin{tabular}{|c|c|c|c|c|c|c|c|c|c|}
\hline \multirow{2}{*}{\multicolumn{2}{|c|}{ Variate }} & \multicolumn{2}{|c|}{ Good } & \multicolumn{2}{|c|}{ Normal } & \multicolumn{2}{|c|}{ Bad } & \multirow[t]{2}{*}{$\chi^{2}$} & \multirow[t]{2}{*}{$P$} \\
\hline & & Number & $\%$ & Number & $\%$ & Number & $\%$ & & \\
\hline \multirow[t]{3}{*}{ Age } & $60 \sim 65$ & 58 & 38.9 & 38 & 28.4 & 0 & 0.0 & \multirow[t]{3}{*}{8.167} & \multirow[t]{3}{*}{0.043} \\
\hline & $66 \sim 70$ & 39 & 26.2 & 27 & 20.1 & 3 & 75.0 & & \\
\hline & $\geqq 71$ & 52 & 34.9 & 69 & 51.5 & 1 & 25.0 & & \\
\hline \multirow[t]{2}{*}{ Gender } & Male & 96 & 64.4 & 88 & 65.2 & 3 & 75.0 & \multirow[t]{2}{*}{0.198} & \multirow[t]{2}{*}{0.906} \\
\hline & Female & 53 & 35.6 & 47 & 34.8 & 1 & 25.0 & & \\
\hline \multirow[t]{4}{*}{ Education level } & Primary and below & 14 & 9.4 & 26 & 19.4 & 0 & 0.0 & \multirow[t]{4}{*}{17.424} & \multirow[t]{4}{*}{0.008} \\
\hline & Junior school & 50 & 33.5 & 52 & 38.8 & 0 & 0.0 & & \\
\hline & High school or technical secondary school & 53 & 35.6 & 37 & 27.6 & 4 & 100.0 & & \\
\hline & College degree or above & 32 & 21.5 & 19 & 14.2 & 0 & 0.0 & & \\
\hline \multirow{3}{*}{$\begin{array}{ll}\text { Career } & \text { before } \\
\text { retirement } & \end{array}$} & Institution or soldiers & 37 & 25.0 & 26 & 19.7 & 1 & 25.0 & \multirow[t]{3}{*}{16.210} & \multirow[t]{3}{*}{0.003} \\
\hline & Commercial or industrial class & 108 & 73.0 & 87 & 65.9 & 2 & 50.0 & & \\
\hline & Individual or agricultural class & 3 & 2.0 & 19 & 14.4 & 1 & 25.0 & & \\
\hline \multirow[t]{4}{*}{ Monthly pension } & $\leqq 1500$ & 7 & 4.9 & 16 & 16.0 & 0 & 0.0 & \multirow[t]{4}{*}{12.568} & \multirow[t]{4}{*}{0.006} \\
\hline & $1501 \sim 3000$ & 99 & 69.7 & 89 & 68.0 & 4 & 100.0 & & \\
\hline & $3001 \sim 4500$ & 29 & 20.5 & 13 & 9.9 & 0 & 0.0 & & \\
\hline & $\geqq 4501$ & 7 & 4.9 & 8 & 6.1 & 0 & 0.0 & & \\
\hline \multirow[t]{5}{*}{ Insurance } & None & 8 & 5.4 & 8 & 6.1 & 0 & 0.0 & \multirow[t]{5}{*}{26.960} & \multirow[t]{5}{*}{0.001} \\
\hline & Urban and rural residents basic medical insurance & 14 & 9.5 & 39 & 29.5 & 2 & 50.0 & & \\
\hline & urban employees ' health insurance system & 115 & 77.7 & 73 & 55.3 & 1 & 25.0 & & \\
\hline & urban employees ' health insurance system & 11 & 7.4 & 10 & 7.6 & 1 & 25.0 & & \\
\hline & Commercial insurance & 0 & 0.0 & 2 & 1.5 & 0 & 0.0 & & \\
\hline \multirow[t]{3}{*}{ Social trust } & Bad & 43 & 28.9 & 59 & 43.7 & 2 & 50.0 & 9.206 & 0.010 \\
\hline & Normal & 79 & 53.0 & 63 & 46.7 & 2 & 50.0 & & \\
\hline & Good & 27 & 18.1 & 13 & 9.6 & 0 & 0.0 & & \\
\hline \multirow[t]{3}{*}{ Public participation } & Bad & 62 & 41.6 & 69 & 51.1 & 1 & 25.0 & 8.942 & 0.011 \\
\hline & Normal & 59 & 39.6 & 58 & 43.0 & 2 & 50.0 & & \\
\hline & Good & 28 & 18.8 & 8 & 5.9 & 1 & 25.0 & & \\
\hline \multirow{3}{*}{$\begin{array}{ll}\text { Social } & \text { network } \\
\text { connection } & \end{array}$} & Bad & 87 & 58.4 & 79 & 58.5 & 1 & 25.0 & 2.443 & 0.295 \\
\hline & Normal & 46 & 30.9 & 47 & 34.8 & 3 & 75.0 & & \\
\hline & Good & 16 & 10.7 & 9 & 6.7 & 0 & 0.0 & & \\
\hline
\end{tabular}

E. Multiple-factor analysis of the relationship between social capital and the elderly people's health conditions

The elderly people's health condition levels are worked as explained variables, which are statistically significant variables of social capital dimension and the single factor analysis, and then Logic regression model is constructed. Result: age, joining insurance, education level, social trust, and public participation are factors that influence the elderly people's health. See table V. 
TABLE V. RESULTS OF LOGISTIC REGRESSION ANALYSIS ON THE ELDERLY PEOPLE’ HEALTH CONDITIONS ORDINAL CATEGORY DATA

\begin{tabular}{|c|c|c|c|c|c|c|c|}
\hline \multicolumn{2}{|c|}{ Variable name } & \multirow[t]{2}{*}{ Matched group } & \multirow{2}{*}{$\begin{array}{l}\text { Coefficient } \\
-0.042 \\
\end{array}$} & \multirow{2}{*}{$\begin{array}{c}\begin{array}{c}\text { Standard } \\
\text { error }\end{array} \\
0.180 \\
\end{array}$} & \multirow{2}{*}{$\begin{array}{c}\boldsymbol{P} \\
0.019\end{array}$} & \multirow{2}{*}{$\begin{array}{c}\text { OR } \\
0.959 \\
\end{array}$} & \multirow{2}{*}{$\begin{array}{c}\text { OR: } \mathbf{9 5 \% C I} \\
0.078 \sim 0.215 \\
\end{array}$} \\
\hline Age & & & & & & & \\
\hline Monthly Retirement Payment & & & 0.481 & 0.266 & 0.071 & 1.617 & $0.025 \sim 0.168$ \\
\hline Career before retirement & Informal career & Formal career & -0.558 & 0.294 & 0.058 & 0.572 & $-0.093 \sim 0.088$ \\
\hline Medical insurance & None & Some & -1.071 & 0.313 & 0.001 & 0.343 & $-0.077 \sim-0.007$ \\
\hline Education level & $\begin{array}{l}\text { Technical high school or } \\
\text { college degree }\end{array}$ & $\begin{array}{l}\text { Junior middle school and } \\
\text { the following }\end{array}$ & 0.384 & 0.275 & 0.164 & 1.468 & $-0.042 \sim 1.003$ \\
\hline & $\begin{array}{l}\text { Junior College and the } \\
\text { following }\end{array}$ & & 0.927 & 0.385 & 0.016 & 2.527 & $-1.135 \sim 0.179$ \\
\hline Social trust degree & & & 0.146 & 0.035 & 0.000 & 1.158 & $-1.684 \sim-0.458$ \\
\hline Public participation degree & & & 0.096 & 0.037 & 0.009 & 1.101 & $-0.156 \sim 0.923$ \\
\hline Social network connection level & & & -0.003 & 0.461 & 0.956 & 0.997 & $0.173 \sim 1.681$ \\
\hline
\end{tabular}

\section{Discussion AND AdVICE}

\section{A. Discussion}

1) The impact on the elderly people according to different social capital measurement

According to the survey results, the perceived health condition is related to social trust level and public participation level. If the elderly people actively enjoy life and have high level of public participation in communities and even more daily public places, they will have more social trust and social values, which is called social trust level. Social can improve the health of the elderly people to some degree by gaining more social security and sense of self-identity, then having higher self-induction health level. The survey result showed residents' health level is positively influenced by social equity and identity which happen to as same as Wang jiangrong and other professor's conclusion. In addition, other foreign scholars have found that "interpersonal trust" is a key protective factor for residents to keep high health condition by researches ${ }^{[8]}$.

Apart from social trust level, public participation has an effect on the elderly people's perceiver-health conditions. Social public participation means they volunteer for the community or neighborhood committees of rich and colorful activities of the organization. The elderly people make up for the sense of lost after retirement by adding social public participation. Meanwhile, it helps the elderly people reduce loneliness and enrich the spiritual and cultural life by participating in rich activities together, and it helps improve communications among the elderly people then adjust and improve their own bad feelings. Social participation helps the elderly people develop their physical and mental health to some degree. The result is the same as self-reported health and organizational participation ${ }^{[7]}$. Xu Ling ${ }^{[9]}$ and other professors have discovered that those who have less connection with neighborhood and relatives and hardly join in social parties have lower self-induction health score. But there is a different view from previous scholars that there isn't obvious relationship between the perceived health of the elderly people and social network. Such as the research made by Xu Ling ${ }^{[10]}$ and other scholars that there exists a close relationship between social networks and perceived health among the elderly people in China cities, which means maybe the definitions of "social network relationship" are various.
2) The impact of health conditions of the elderly people with different features

According to the survey result, the health conditions will go down with the increase of their age. Those with lower education level have worse health conditions; maybe this is the result of their unscientific life habits and quality. Conclusions can also be gotten that the health conditions of those who have no medical insurance are better than those who have urban residents' basic medical insurance. That's because those who have medical insurance have higher sense of health than those who have no medical insurance. Meanwhile, with the increase of the medical care costs, the elderly people have to assume their medical care costs more by themselves, which will increase more burdens to the retired elderly people, and it will influence the degree of satisfaction to the medical and health services. As a result, some of them give up being treated directly, which will cause the reduction of their health conditions. From this view, free medical service, urban employees ' health insurance system and commercial insurance all have obvious influence on the health conditions of the elderly people. The result is the same as Meng Qinqin ${ }^{[11]}$,s conclusion that there is independent effect between the type of medical treatment insurance and the health conditions of the elderly people. We can also conclude that the higher the pension is, the higher the level of the health conditions are, which means their ability to pay is the safeguard to their health. Both Li Shixue $^{[12]}$, s research on health conditions of the people and Wang Fangdao ${ }^{[13]}$,s research on perceived-health condition based on China's rural elderly people have found that the higher the income of residents is, the level of health condition is, which is the same as this survey.

\section{B. Advice}

1) Improve the level of social trust and level of public participation of the community elderly people

Improving the level of social trust and level of public participation of the elderly people is based on the health of the elderly people. With the help of the society and the government, communal facilities should be improved to satisfy their spiritual and cultural needs and enrich their sparetime life. Under the premise of the elderly health, the elderly people should be provided platforms for sports and exercise and carry out a variety of multiple activities, such as playing chess for those disabled elderly people or playing table tennis for those hale and hearty ones. Community residents committees should 
help a lot such as delivering speeches about psychological counseling and daily fitness to help the elderly people sets up the correct understanding of health and increase social presence and inner sense of belonging based on the understanding of each other. Carrying out cultural exchange activities regularly can enrich their spiritual and cultural life then improve their health conditions.

Thus it can be seen that the elderly people should be avoided to have negative attitude towards life and social activities by managing the elderly people in the community, and we should help the elderly people set up a deeply loves the life, positive attitude and help them increase confidence then up to a goal that promote them to join social activities to improve their health level. Also, it is an important measure to coordinate an ageing population by helping the elderly people raise the social trust level and public participation level ${ }^{[14]}$.

\section{2) Reduce the proportion of health care pays}

The government should increase the medicare reimbursement ratio and expand the health insurance coverage for the elderly people in Tianjin area. In addition, Health benefits to life should be strengthened to those who have lower education level, lower retirement income, higher age, lower retired enterprise welfare treatment and disabilities. The government can help the elderly people set up health concept and the selfhealth care consciousness by helping communities deliver health speeches for the elderly people. By increasing the money spent on the medical care, existing medical and health resources will be promoted and existing medical security system will be improved then medical treatment at the elderly people's own expense proportion will be declined. Expenditure of the whole will be used as allowance for the elderly people's insurance to make them joining insurance and the medical reimbursement process should be simplified and managed. Let commercial health insurance makes up for the lack of social insurance, and support and encourage commercial insurance to provide more comprehensive products for medical insurance, and raise the will of the elderly people to buy commercial insurance ${ }^{[15]}$. The perfection of the health insurance system can reduce the fear of the insured when seeing doctors. Also, the designment of medical care insurance system can be used to guide and specify the effect of the correct ways to seek medical advice, and it is good to improve the overall social welfare ${ }^{[16]}$. We should correct the unreasonable phenomenon in medical insurance system, set up sophisticated and harmony medical insurance system, remove the fear of the elderly people, and finally improve the health level of them.

\section{REFERENCES}

[1] http://www.stats.gov.cn/tjsj/pcsj/rkpc/6rp/indexch.htm

[2] McKenzie,K.Whitley, R. and Weich, [S]. Social capital and mental health.Britais Journal of Psychia-try.2002, 181(4): 280-283.

[3] Tang Ying. Analysis on rural residents' perceived health and the influence factors in Shandong Province, [D]. Jinan, Shandong University, 2006.(In Chinese)

[4] Zhang Qiumei. Analysis on the relationship between rural residents' perceived health and mental health and the influence factors in Weihai, Jinan, Shandong University, 2007.(In Chinese)

[5] Sun Xiaojie. The relationship between social capital and urban residents' health and fair-an empirical research from Xining and Yinchuan, [D]. Jinan, Shandong University, 2008.(In Chinese)

[6] Li Yuxia, research on Chinese rural residents' social capital current situation and the relationship between it and health [D]. Jinan, Shandong University, 2007.(In Chinese)

[7] Wang Jiangrong, Zhang Tuohong. The relationship between social capital factors of the Chinese adult residents and health [J]. Journal of Beijing university (medical edition), 2012,3(44): 394-396.(In Chinese)

[8] Poortinga W. Social capital: an individual or collectivw resource for health[J]. Soc Sci Med, 2006, 62(2):292-302.

[9] Xu Ling, Lei Peng, Wu Yaochun. Research on the relationship between perceived health of the Chinese unban elderly people and social network[J]. Chinese Journal of Health Education, 2011,7(27): 496497.(In Chinese)

[10] Zhou Ting. Analysis on China's urban elderly medical welfare and countermeasure research [J]. Shanghai Economic Review, 2012,277(8):111-114.(In Chinese)

[11] Meng Qinqin, Zhang Tuohong. The relationship between China's adult residents of self-evaluation of health related factors and social capital [J] Journal of Beijing university (medical edition), 2010,42(3):258-263.(In Chinese)

[12] Li Shixue, Lv Shaoli, Research of the crowd self-induction health score and influencing factors [J], China Public Health, 2003,19(6):678-681.(In Chinese)

[13] Wang Fangren, Ruan Shaorui. Analysis on the perceived health condition of the rural elderly and social and psychological factors [J]. Medicine and society, 1999,12(2):6-8.(In Chinese)

[14] Yu Yanqiu. Discussion on elderly medical ethics in 21th century [J]. Medical and social medical ethics. 2001.14 (5) :42-43.(In Chinese)

[15] Wang Xinjun, Zheng Chao. The influence of medical insurance on the elderly people's health cost and health[J]. Journal of Finance and Economics, 2014,40(12):6-745.(In Chinese)

[16] Xue Weiling, Lu Jiehua. Research on the elderly health care costs based on medical insurance [J]. Population Journal, 2012,191(1):61-67.(In Chinese) 